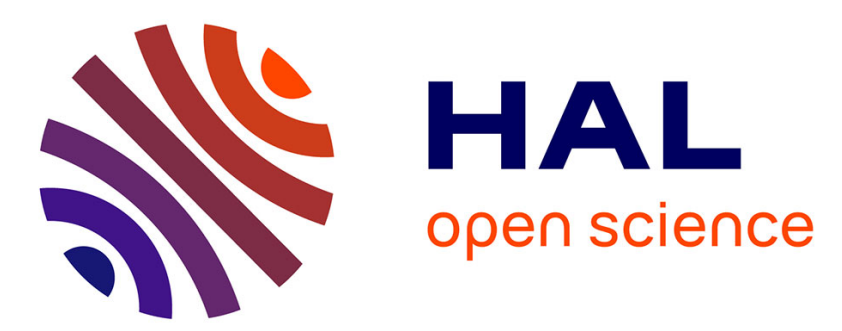

\title{
Astrocytes Shape Axonal Signaling
}

Dominique Debanne, Sylvain Rama

\section{To cite this version:}

Dominique Debanne, Sylvain Rama. Astrocytes Shape Axonal Signaling. Science Signaling, 2011, 4 (162), pe11. 10.1126/scisignal.2001884 . hal-01771777

\section{HAL Id: hal-01771777 \\ https://hal-amu.archives-ouvertes.fr/hal-01771777}

Submitted on 19 Apr 2018

HAL is a multi-disciplinary open access archive for the deposit and dissemination of scientific research documents, whether they are published or not. The documents may come from teaching and research institutions in France or abroad, or from public or private research centers.
L'archive ouverte pluridisciplinaire HAL, est destinée au dépôt et à la diffusion de documents scientifiques de niveau recherche, publiés ou non, émanant des établissements d'enseignement et de recherche français ou étrangers, des laboratoires publics ou privés. 
Astrocytes Shape Axonal Signaling

Dominique Debanne1,2,* and Sylvain Rama1,2

1INSERM, U641, Marseille, 13344 France.

2Université de la Méditerranée, Faculté de Médecine secteur nord, IFR 11, Marseille, 13344 France.

*Corresponding author. E-mail, dominique.debanne@univmed.fr

See allHide authors and affiliations

Sci. Signal. 01 Mar 2011:

Vol. 4, Issue 162, pp. pe11

DOI: $10.1126 /$ scisignal.2001884

Dominique Debanne

INSERM, U641, Marseille, 13344 France.Université de la Méditerranée, Faculté de Médecine secteur nord, IFR 11, Marseille, 13344 France.

For correspondence: dominique.debanne@univmed.fr

Sylvain Rama

INSERM, U641, Marseille, 13344 France. Université de la Méditerranée, Faculté de Médecine secteur nord, IFR 11, Marseille, 13344 France. 
Abstract

Axons perform two major functions that underlie the electrical activity of neurons. They generate action potentials in the axon initial segment and enable propagation of action potentials to the presynaptic terminal to trigger chemical signaling to postsynaptic neurons. The action potential waveform can be modulated by intrinsic factors such as axon geometry or biophysical properties that eventually enhance neurotransmitter release. This view has been extended by new evidence showing that extrinsic signals arising from astrocytes also control the action potential waveform and influence synaptic strength. This plasticity is independent of the tripartite structure formed by astrocytes with the neuronal pre- and postsynaptic elements. By shaping axonal action potential waveform, astrocytes act as extrinsic instructors of glutamatergic transmission in the hippocampus.

Axons are involved in two major operations that determine neuronal output: (i) the initiation of the action potential at the axon initial segment and (ii) the active propagation of action potentials from this proximal region of the axon to the axon terminal $(1,2)$. Generally, axons are considered to be reliable transmission cables in which stable propagation occurs once an action potential is generated. However, increasing evidence suggests that the axon is also the locus of several operations that determine signal processing in synaptic circuits, neuronal timing, and synaptic efficacy (3). For instance, in response to certain stimuli action potentials fail to propagate $(4,5)$ or propagate backward (6) at axonal branch points. Repetitive firing leads to axon-specific spike broadening because of inactivation of potassium channels that subsequently enhances presynaptic glutamate release (7). Axons integrate slow synaptic potentials arising from the somatic and dendritic compartments that modulate voltage-gated ion channels in the presynaptic terminal and alter spikeevoked synaptic transmission (Fig. 1, A and B). For instance, slow depolarization below the spike threshold increases synaptic strength (8-12). Thus, axons signal both digital (namely, action potentials) and analog (namely, slow synaptic potentials) events (13) through the inactivation of axonal potassium channels or the modulation of basal calcium concentrations and spike-evoked increases in terminals $(14,15)$. These mechanisms of regulating axonal processing are intrinsic because they rely on both axon geometry and the biophysical state of axonal ion channels. Sasaki et al. (16) now extend this view by showing that extrinsic signals arising from astrocytes - the largest class of glial cells in the brain - can also transiently modulate the width of action potentials in axons. Using an elegant combination of electrophysiological and confocal imaging techniques, the group of Ikegaya showed that stimulation of peri-axonal astrocytes causes broadening of action potentials in axons of CA3 pyramidal neurons through the activation of AMPA-type glutamate receptors (Fig. 1C). The consequence of spike broadening is an intra-axonal increase in calcium concentration that favors glutamate release at en passant boutons. Thus, local activation of the astrocytic network can modulate axonal properties and, in turn, facilitate synaptic transmission. 


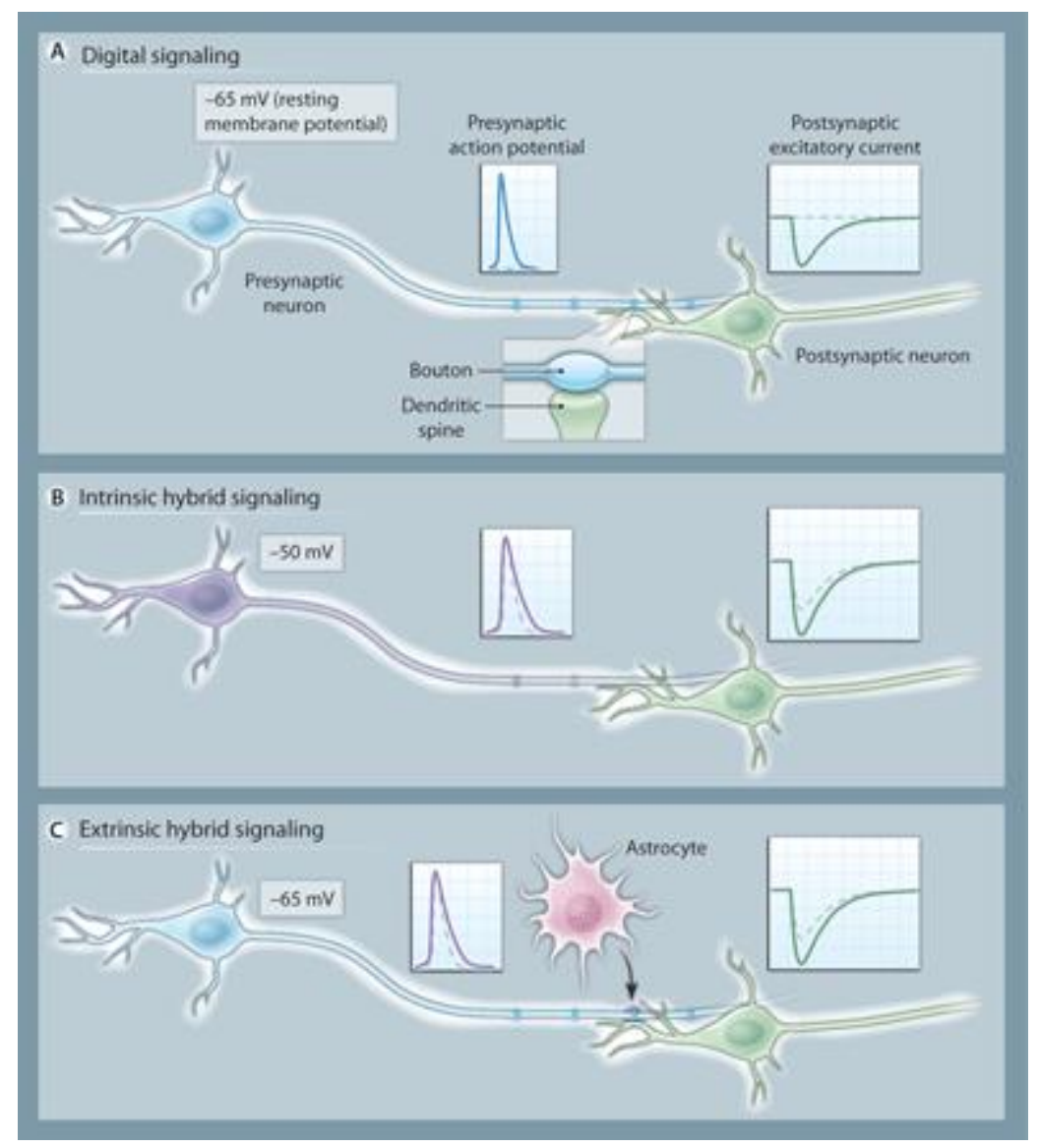

Fig. 1

Multiple modes of cortical axon signaling. (A) Digital signaling. Postsynaptic responses (gray traces) are determined in an all-or-none fashion by the presynaptic action potential generated in the axon initial segment and propagated along the axon. (B) Intrinsic digital-analog (hybrid) signaling.

Propagation of subthreshold depolarization $(-50 \mathrm{mV})$ from the somatodendritic compartment to the axon enhances synaptic transmission triggered by action potentials. In this case, the action potential width is extended and thus facilitates neurotransmitter release. (C) Extrinsic digital-analog (hybrid) signaling. Glutamate released by the astrocyte depolarizes the axon locally, increases the width of the action potential, and facilitates synaptic transmission [adapted from (16)].

Other studies have also stressed the importance of astrocytes in fast synaptic transmission. Astrocytes occupy a strategic position in the brain. Because of their highly ramified morphology, they tightly interact with the pre- and postsynaptic neuronal elements to form a tripartite synaptic complex $(17,18)$. The glutamate transporters on the surface of astrocytes endow these cells with the ability to regulate synaptic transmission by controlling glutamate diffusion and concentration in the extracellular space $(19,20)$. As a consequence, astrocytic coverage determines short-term plasticity of synaptic transmission through the modulation of presynaptic glutamate receptors (21). There is now strong evidence that slowly occurring (seconds to minutes) elevations in intracellular calcium concentration are triggered in astrocytes after activation of $\mathrm{G}$ protein-coupled receptors by synaptically released neurotransmitter. A striking consequence of this astrocytic activity seems to be the capacity of astrocytes to release glutamate and other gliotransmitters, such as adenosine $5^{\prime}$ triphosphate and d-serine, in a soluble $\mathrm{N}$-ethylmaleimide-sensitive factor (NSF) attachment protein (SNAP) receptor (SNARE)-dependent manner $(22,23)$. In fact, glutamate released from astrocytes 
generates slow transient currents in pyramidal neurons that are mediated by the activation of $\mathrm{N}$ methyl-d-aspartate (NMDA) receptors (24). Astrocytes also play the role of cellular relay between pyramidal neurons by mediating depolarization-induced facilitation of synaptic transmission in the CA1 region (25). The release of $d$-serine from astrocytes has been suggested to facilitate induction of long-term synaptic potentiation by its modulatory action on postsynaptic NMDA receptors $(26,27)$, although another study has shown that long-term potentiation induction is not modulated by astrocyte Ca2+ signaling (28). The data of Sasaki et al. (16) is consistent with the release of glutamate by astrocytes because axonal spike broadening was blocked by an antagonist against glutamate receptors. Beyond their classical modulation of synaptic transmission by the recapture of glutamate or the release of gliotransmitter that affect the pre- or postsynaptic elements, astrocytes are now shown to regulate neuronal communication by directly acting on the axon, upstream to the tripartite structure. Axonal spike broadening was not affected by inhibiting glutamate transporters or by buffering intraneuronal calcium, but was abolished by an AMPA receptor antagonist and mimicked by direct local application of glutamate to the axon. Notably, the amount of synaptic facilitation obtained at CA3-CA3 connections ( $12 \%)$ is similar to that observed when the axonal spike is enlarged by depolarization of the cell body (11). However, a striking difference between these two modulations is that the astrocyte-dependent modulation of spike width affects only a relatively small portion of the axon, whereas depolarization of the cell body is expected to broaden the spike in many boutons along the axon over a distance defined by the axon space constant (Fig. 1C).

Glia-axon interactions were initially thought to be mainly restricted to the production of the myelin sheath by oligodendrocytes that covers axons and allows faster conduction velocity $(29,30)$. However, accumulating evidence has revealed interactions between astrocytes and axons. In myelinated axons, perinodal astrocyte processes establish contact with the nodal membrane of the axon to buffer ion concentrations in the extracellular perinodal space $(31,32)$. The study of Sasaki et al. (16) broadens this view by showing that astrocytes also interact with axons to shape neuronal transmission. However, many questions remain to be addressed. First, a single astrocyte covers a spherical volume with a diameter of $\sim 40 \mu \mathrm{m}$ (33). Therefore, activity of an astrocyte may affect a large population of axons, creating volumes of enhanced synaptic transmission. The consequences of this regulation on hippocampal network activity must also be explored. Second, astrocytes display spontaneous calcium fluctuations that propagate over the astrocytic network by way of gap junctions (34). Calcium propagation into specific astrocytes or astrocytic processes may influence interneuronal transmission, and the general principles governing the regulation of cell-cell communication within these networks have yet to be discovered. Third, the mechanisms by which the many functions of astrocytes in the central nervous system (neurovascular coupling, control of ionic and metabolism environment in the neuropil, partners of the tripartite synapse, and regulators of axonal spike waveform) are coordinated remain to be clarified. Fourth, astrocytic calcium activity is at least two orders of magnitude slower than that of sodium spikes. This implies that astrocytes are probably implicated in regulatory mechanisms that differ from the fast coincidence-detection processes classically described in the brain. Rather, astrocytes may be implicated in slow neuronal adaptation, such as homeostatic mechanisms or developmental regulation. It can be expected that in the future, a complete picture integrating these previously unknown facets of neuron-glia interactions will emerge.

References and Notes

1. M. H. Kole, S. U. Ilschner, B. M. Kampa, S. R. Williams, P. C. Ruben, G. J. Stuart. Action potential generation requires a high sodium channel density in the axon initial segment. Nat. Neurosci. 11, 178-186 (2008). doi:10.1038/nn2040 pmid:18204443 
2. B. D. Clark, E. M. Goldberg, B. Rudy. Electrogenic tuning of the axon initial segment. Neuroscientist 15, 651-668 (2009). doi:10.1177/1073858409341973 pmid:20007821

3. D. Debanne. Information processing in the axon. Nat. Rev. Neurosci. 5, 304-316 (2004). doi:10.1038/nrn1397 pmid:15034555

4. Y. Grossman, I. Parnas, M. E. Spira. Differential conduction block in branches of a bifurcating axon. J. Physiol. 295, 283-305 (1979). pmid:521937

5. D. Debanne, N. C. Guérineau, B. H. Gähwiler, S. M. Thompson. Action-potential propagation gated by an axonal IA-like K+ conductance in hippocampus. Nature 389, 286-289 (1997).

doi:10.1038/38502 pmid:9305843

6. S. A. Baccus. Synaptic facilitation by reflected action potentials: Enhancement of transmission when nerve impulses reverse direction at axon branch points. Proc. Natl. Acad. Sci. U.S.A. 95, 83458350 (1998). doi:10.1073/pnas.95.14.8345 pmid:9653189

7. J. R. Geiger, P. Jonas. Dynamic control of presynaptic Ca2+ inflow by fast-inactivating K+ channels in hippocampal mossy fiber boutons. Neuron 28, 927-939 (2000). doi:10.1016/S08966273(00)00164-1 pmid:11163277

8. T. Shimahara, B. Peretz. Soma potential of an interneurone controls transmitter release in a monosynaptic pathway in Aplysia. Nature 273, 158-160 (1978). doi:10.1038/273158a0 pmid:25388

9. H. Alle, J. R. Geiger. Combined analog and action potential coding in hippocampal mossy fibers. Science 311, 1290-1293 (2006). doi:10.1126/science.1119055 pmid:16513983

10. Y. Shu, A. Hasenstaub, A. Duque, Y. Yu, D. A. McCormick. Modulation of intracortical synaptic potentials by presynaptic somatic membrane potential. Nature 441, 761-765 (2006). doi:10.1038/nature04720 pmid:16625207

11. M. H. Kole, J. J. Letzkus, G. J. Stuart. Axon initial segment Kv1 channels control axonal action potential waveform and synaptic efficacy. Neuron 55, 633-647 (2007).

doi:10.1016/j.neuron.2007.07.031 pmid:17698015

12. J. M. Christie, D. N. Chiu, C. E. Jahr. Ca2+-dependent enhancement of release by subthreshold somatic depolarization. Nat. Neurosci. 14, 62-68 (2011). doi:10.1038/nn.2718 pmid:21170054

13. B. Clark, M. Häusser. Neural coding: Hybrid analog and digital signalling in axons. Curr. Biol. 16, R585-R588 (2006). doi:10.1016/j.cub.2006.07.007 pmid:16890514

14. G. B. Awatramani, G. D. Price, L. O. Trussell. Modulation of transmitter release by presynaptic resting potential and background calcium levels. Neuron 48, 109-121 (2005).

doi:10.1016/j.neuron.2005.08.038 pmid:16202712

15. Y. Yu, C. Maureira, X. Liu, D. McCormick. P/Q and $\mathrm{N}$ channels control baseline and spike-triggered calcium levels in neocortical axons and synaptic boutons. J. Neurosci. 30, 11858-11869 (2010). doi:10.1523/JNEUROSCI.2651-10.2010 pmid:20810905

16. T. Sasaki, N. Matsuki, Y. Ikegaya. Action-potential modulation during axonal conduction. Science 331, 599-601 (2011). doi:10.1126/science.1197598 pmid:21292979

17. A. Araque, V. Parpura, R. P. Sanzgiri, P. G. Haydon. Tripartite synapses: Glia, the unacknowledged partner. Trends Neurosci. 22, 208-215 (1999). doi:10.1016/S0166-2236(98)01349-6 pmid:10322493 
18. D. T. Theodosis, D. A. Poulain, S. H. Oliet. Activity-dependent structural and functional plasticity of astrocyte-neuron interactions. Physiol. Rev. 88, 983-1008 (2008). doi:10.1152/physrev.00036.2007 pmid:18626065

19. J. D. Rothstein, M. Dykes-Hoberg, C. A. Pardo, L. A. Bristol, L. Jin, R. W. Kuncl, Y. Kanai, M. A. Hediger, Y. Wang, J. P. Schielke, D. F. Welty. Knockout of glutamate transporters reveals a major role for astroglial transport in excitotoxicity and clearance of glutamate. Neuron 16, 675-686 (1996). doi:10.1016/S0896-6273(00)80086-0 pmid:8785064

20. D. E. Bergles, C. E. Jahr. Glial contribution to glutamate uptake at Schaffer collateral-commissural synapses in the hippocampus. J. Neurosci. 18, 7709-7716 (1998). pmid:9742141

21. S. H. Oliet, R. Piet, D. A. Poulain. Control of glutamate clearance and synaptic efficacy by glial coverage of neurons. Science 292, 923-926 (2001). doi:10.1126/science.1059162 pmid:11340204

22. P. Jourdain, L. H. Bergersen, K. Bhaukaurally, P. Bezzi, M. Santello, M. Domercq, C. Matute, F. Tonello, V. Gundersen, A. Volterra. Glutamate exocytosis from astrocytes controls synaptic strength. Nat. Neurosci. 10, 331-339 (2007). doi:10.1038/nn1849 pmid:17310248

23. N. B. Hamilton, D. Attwell. Do astrocytes really exocytose neurotransmitters? Nat. Rev. Neurosci. 11, 227-238 (2010). doi:10.1038/nrn2803 pmid:20300101

24. M. C. Angulo, A. S. Kozlov, S. Charpak, E. Audinat. Glutamate released from glial cells synchronizes neuronal activity in the hippocampus. J. Neurosci. 24, 6920-6927 (2004).

doi:10.1523/JNEUROSCI.0473-04.2004 pmid:15295027

25. M. Navarrete, A. Araque. Endocannabinoids potentiate synaptic transmission through stimulation of astrocytes. Neuron 68, 113-126 (2010). doi:10.1016/j.neuron.2010.08.043 pmid:20920795

26. A. Filosa, S. Paixão, S. D. Honsek, M. A. Carmona, L. Becker, B. Feddersen, L. Gaitanos, Y. Rudhard, R. Schoepfer, T. Klopstock, K. Kullander, C. R. Rose, E. B. Pasquale, R. Klein. Neuron-glia communication via EphA4/ephrin-A3 modulates LTP through glial glutamate transport. Nat. Neurosci. 12, 1285-1292 (2009). doi:10.1038/nn.2394 pmid:19734893

27. C. Henneberger, T. Papouin, S. H. Oliet, D. A. Rusakov. Long-term potentiation depends on release of D-serine from astrocytes. Nature 463, 232-236 (2010). doi:10.1038/nature08673 pmid:20075918

28. C. Agulhon, T. A. Fiacco, K. D. McCarthy. Hippocampal short- and long-term plasticity are not modulated by astrocyte Ca2+ signaling. Science 327, 1250-1254 (2010).

doi:10.1126/science.1184821 pmid:20203048

29. S. G. Waxman. Axon-glia interactions: Building a smart nerve fiber. Curr. Biol. 7, R406-R410 (1997). doi:10.1016/S0960-9822(06)00203-X pmid:9210363

30. Y. Yamazaki, Y. Hozumi, K. Kaneko, T. Sugihara, S. Fujii, K. Goto, H. Kato. Modulatory effects of oligodendrocytes on the conduction velocity of action potentials along axons in the alveus of the rat hippocampal CA1 region. Neuron Glia Biol. 3, 325-334 (2007). doi:10.1017/S1740925X08000070 pmid:18634564 
31. C. Hildebrand, S. G. Waxman. Postnatal differentiation of rat optic nerve fibers: Electron microscopic observations on the development of nodes of Ranvier and axoglial relations. J. Comp. Neurol. 224, 25-37 (1984). doi:10.1002/cne.902240103 pmid:6715578

32. J. A. Black, S. G. Waxman. The perinodal astrocyte. Glia 1, 169-183 (1988). doi:10.1002/glia.440010302 pmid:2976037

33. K. Ogata, T. Kosaka. Structural and quantitative analysis of astrocytes in the mouse hippocampus. Neuroscience 113, 221-233 (2002). doi:10.1016/S0306-4522(02)00041-6 pmid:12123700

34. C. Giaume, A. Koulakoff, L. Roux, D. Holcman, N. Rouach. Astroglial networks: A step further in neuroglial and gliovascular interactions. Nat. Rev. Neurosci. 11, 87-99 (2010). doi:10.1038/nrn2757 pmid:20087359

35. Acknowledgments: We thank M. Seagar and J. M. Goaillard for helpful comments on the manuscript. Funding: This work was supported by Institut National de la Santé et de la Recherche Médicale, Centre National de la Recherche Scientifique, Agence Nationale de la Recherche, and Région Provence-Alpes-Côte d'Azur. 